\title{
Evaluation of the Acute Hepatoprotective Potential of Hydroethanolic Extract of Duranta erecta L. Parts
}

\author{
Shadrack Donkor $\mathbb{D}^{1,2}$ Christopher Larbie ${ }^{10},{ }^{2}$ Gustav Komlaga, ${ }^{3}$ \\ and Benjamin Obukowho Emikpe ${ }^{4}$ \\ ${ }^{1}$ Applied Radiation Biology Centre, Radiological and Medical Sciences Research Institute, Ghana Atomic Energy Commission, \\ Legon, Accra, Ghana \\ ${ }^{2}$ Department of Biochemistry and Biotechnology, Kwame Nkrumah University of Science and Technology (KNUST), \\ Kumasi, Ghana \\ ${ }^{3}$ Department of Pharmacognosy, Kwame Nkrumah University of Science and Technology (KNUST), Kumasi, Ghana \\ ${ }^{4}$ Department of Pathobiology, School of Veterinary Medicine, Kwame Nkrumah University of Science and Technology (KNUST), \\ Kumasi, Ghana
}

Correspondence should be addressed to Shadrack Donkor; shadrachdonkor2000@gmail.com

Received 14 July 2020; Accepted 27 November 2020; Published 9 December 2020

Academic Editor: Anthony DeCaprio

Copyright (c) 2020 Shadrack Donkor et al. This is an open access article distributed under the Creative Commons Attribution License, which permits unrestricted use, distribution, and reproduction in any medium, provided the original work is properly cited.

\begin{abstract}
Liver disease is a major health problem and its treatment is costly in most developing countries with attendant adverse effects. This study aimed at determining the acute hepatoprotective efficacy of Duranta erecta hydroethanolic extracts of leaves, ripe and unripe fruits against $\mathrm{CCl}_{4^{-}}$, and acetaminophen-induced hepatotoxicity in animals. Materials and Methods. CCl 4 ( $1 \mathrm{~mL} / \mathrm{kg}$ body weight in olive oil) and acetaminophen $(500 \mathrm{mg} / \mathrm{kg}$ b.wt) were used to induce hepatotoxicity in the animals. Animals were treated with extracts at $250 \mathrm{mg} / \mathrm{kg}$ b.wt and standard drug, silymarin $(100 \mathrm{mg} / \mathrm{kg})$, for 7 days. Hepatoprotective efficacy was assessed by assaying serum biochemical markers such as alanine aminotransferase (ALT), aspartate aminotransferase (AST), alkaline phosphatase (ALP), gamma-glutamyl transferase $(\gamma \mathrm{GT})$, bilirubin (Bil), antioxidative biomarkers including reduced glutathione (GSH), glutathione peroxidase (GPx), glutathione transferase (GST), superoxide dismutase (SOD), malondialdehyde (MDA), hydrogen peroxidase $\left(\mathrm{H}_{2} \mathrm{O}_{2}\right)$, and nitric oxide $(\mathrm{NO})$, as well as histological observations. Results. Exposure of the animals to $\mathrm{CCl}_{4}$ and acetaminophen resulted in liver injury as evidenced by elevated ALT, AST, ALP, $\gamma$ GT, Bil, MDA, $\mathrm{H}_{2} \mathrm{O}_{2}$, and NO levels with resultant derangement in liver microarchitecture. Pretreatment with hydroethanolic extracts, particularly ripe fruits of Duranta erecta, led to a reduction in these indicators and an increase in GSH, GPx, GST, and SOD levels. Biochemical data were supported by improvement in liver structure. Conclusion. The findings suggest that hydroethanolic Duranta erecta ripe fruits extract possesses hepatoprotective and antioxidative activities against $\mathrm{CCl}_{4}$ - and acetaminophen-induced toxicity and could be developed as a potent agent for drug-induced liver diseases.
\end{abstract}

\section{Introduction}

The liver is the largest organ in the human body and plays a critical role in influencing many life processes. It regulates the upkeep of internal environment through its multiple functions. This makes the liver highly vulnerable to substances that may be harmful to its cells, leading to liver injury or damage. Liver diseases are still a major health problem worldwide with a mortality rate of 2 million deaths per year
[1] and affect people of all ages throughout the world. In Africa, particularly Ghana, accurate statistics on causespecific mortality is not readily available; thus, there is the possibility to underestimate liver disease as the main cause of most deaths. Several agents, namely, viruses, chemicals, and pollutants are thought to be responsible for liver diseases. Liver diseases can initiate a cascade of events, resulting in extrahepatic morbidities which may eventually culminate into a reduced quality of life and mortality. According to the 
latest WHO data, liver disease-related deaths in Ghana accounted for 3,560 (3.27\%) of the total deaths; Ghana was ranked 17 th in the world with regard to liver disease-related deaths [2]. Treatments for liver diseases are costly in most developing countries. Most of the orthodox or synthetic drugs used in the treatment of liver diseases tend to have adverse effects on other body tissues. There is a need to improve the outcomes for patients with liver diseases with the search for natural products that exhibit low or no adverse effect. This has led to a growing interest in the use of traditional herbal medicines that supposedly possess hepatoprotective activity. Numerous studies have been carried to look out for natural products that exhibit hepatoprotective effects with low adverse reactions [3-6].

Duranta erecta L. (family Verbenaceae) is native to the tropical forest. In Ghana, it is cultivated as an ornamental hedge because of its profuse display of colourful flowers. It has been shown to possess antimicrobial [7], antioxidant [8], antifungal [9], antiparasitic [10], and antiviral [11] activities. The species has previously been demonstrated to contain important phytochemicals, such as flavonoids, phenols, and tannins, which can be exploited in the fight against oxidative stress conditions [8]. Duranta erecta has been used to treat various ailments since antiquity. The fruits have been used in the treatment of malaria and abscesses. The whole plant has been used to treat pneumonia, infertility, and neurological disorders [12]. The pharmacological and medicinal properties of the plant can be attributed to its phytochemical constituents such as durantol, pectolinaringenin, repennoside, repenins, and scutellarein [13].

Common liver injury models employed to screen hepatoprotective drugs include the use of carbon tetrachloride $\left(\mathrm{CCl}_{4}\right)$ and some analgesics such as acetaminophen (paracetamol). The injury produced by these toxicants is because of their reactive metabolites. $\mathrm{CCl}_{4}$ is bioactivated by cytochrome P-450, resulting in the formation of trichloromethyl radical and reactive oxygen species. Trichloromethyl radical reacts with oxygen to form the highly toxic reactive trichloromethyl peroxyl radical, which initiates lipid peroxidation, resulting in a chain of reaction which eventually leads to liver damage [14]. Similarly, the toxicity of acetaminophen is due to a highly reactive metabolite $\mathrm{N}$-acetyl- $p$ benzoquinoneimine, which is activated by cytochrome P-450, leading to oxidation of macromolecules such as lipid and protein [15].

Several pharmacological evaluations of Duranta erecta have been focused on its use as an antidiuretic, antitumour, antibacterial, and anthelmintic agent [16]. Little is known about its hepatoprotective property. The present study was aimed at assessing the protective effect of Duranta erecta hydroethanolic extracts (DRE) of the leaves, ripe fruits, and unripe fruits on carbon tetrachloride $\left(\mathrm{CCl}_{4}\right)$ - and acetaminophen (Para))-induced liver damage in rats using biochemical and histological parameters.

\section{Materials and Methods}

2.1. Chemicals. Biochemical kits for the determination of alanine aminotransferase (ALT), alkaline phosphatase
(ALP), gamma-glutamyl transferase $(\gamma \mathrm{GT})$, total protein, albumin, bilirubin (total and direct), cholesterol, triglycerides, urea, and creatinine were obtained from Elitech, France. Silymarin, carbon tetrachloride $\left(\mathrm{CCl}_{4}\right)$, acetaminophen, epinephrine, 5,5-dithiobis-2-nitrobenzoic acid (DTNB), hydrogen peroxide, reduced glutathione (GSH), sodium azide, ammonium ferrous sulphate, sorbitol, xylenol orange, and thiobarbituric acid (TBA) were purchased from SIGMA (USA). All other reagents were of analytical grade and were obtained from the British Drug Houses (Poole, UK).

2.2. Plant Collection and Extraction. Plant materials (leaves, ripe fruits, and unripe fruits) were collected in October 2017 within the vicinity of the Department of Biochemistry and Biotechnology Annex office, KNUST, and authenticated with voucher number KNUST/HM1/2017/L011 by Dr George Sam at the Department of Herbal Medicine, Faculty of Pharmaceutical Sciences, KNUST. The plant parts were treated and extracted as described previously [8]. Briefly, $60 \mathrm{~g}$ of pulverized leaf and fruit were extracted with $50 \%$ hydroethanol for 48 hours to obtain respective crude extracts; Duranta erecta leaves (DRL), Duranta erecta ripe (DRR), and unripe fruits extract (DRU).

2.3. Animals. Male albino rats $(120-150 \mathrm{~g})$ obtained from the animal facility of the Department of Biochemistry and Biotechnology, KNUST, were used in the study. They were kept under standard laboratory conditions and handled as stipulated in the guidelines of the Committee for the Purpose of Control and Supervision of Experiment on Animals (CPCSEA, New Delhi, India). Animals were housed in aluminium cages, suitably bedded with wood shaving. They were maintained under standard conditions of temperature and humidity and had free access to standard feed and water except for an overnight fast before being sacrificed. All animals were humanely handled during the experiment. In the experimental group of the animals, their body weight was taken into consideration to achieve approximately equal conditions among the groups. Animals were humanely handled according to the Guide for Care and Use of Laboratory Animals [17] and protocol for the animal study was reviewed and approved by a veterinarian on the team.

2.4. Treatments. Forty-four animals (eleven groups, $n=4$ ) were used to study the acute hepatoprotective effect of Duranta erecta extracts on $\mathrm{CCl}_{4}$ and acetaminophen-induced liver damage. Details of experimental design and treatments are shown in Table 1. Group 1 served as vehicle control in both cases, received $1 \mathrm{~mL} / \mathrm{kg}$ body weight (b.wt) of distilled water throughout the experiment. Groups II-VI were treated with $1 \mathrm{~mL} / \mathrm{kg}$ b.wt $\mathrm{CCl}_{4}$ diluted with olive oil (1 : $1 \mathrm{vol} / \mathrm{vol}$ ) for two successive days, the 2 nd to $3 \mathrm{rd}$ day by intraperitoneal (i.p.) injection. Group II animals were maintained as $\mathrm{CCl}_{4}$ control without any drug treatment. Group III received standard hepatoprotective agent $(100 \mathrm{mg} /$ $\mathrm{kg}$ b.wt silymarin orally), from 1 st to 7 th day. Groups IV, V, 
TABLE 1: Grouping of animals for the study.

\begin{tabular}{|c|c|c|}
\hline $\begin{array}{l}\text { Group } \\
\text { number }\end{array}$ & Group name & Treatment \\
\hline I & Normal & Animals orally received $1 \mathrm{~mL} / \mathrm{kg}$ b.wt distilled water daily for 7 days \\
\hline II & $\mathrm{CCl}_{4}$ only & Animals received $1 \mathrm{~mL} / \mathrm{kg}$ b.wt CCl4 dissolved in olive oil $(1: 1 \mathrm{v} / \mathrm{v})$ i.p. on 2 nd and $3 \mathrm{rd}$ days \\
\hline III & Sily $+\mathrm{CCl}_{4}$ & $\begin{array}{l}\text { Animals orally received } 100 \mathrm{mg} / \mathrm{kg} \text { b.wt silymarin dissolved in distilled water daily for } 7 \text { days and } 1 \mathrm{~mL} / \mathrm{kg} \\
\text { b.wt } \mathrm{CCl}_{4} \text { on } 2 \mathrm{nd} \text { and } 3 \mathrm{rd} \text { days }\end{array}$ \\
\hline IV & $\mathrm{DRR}+\mathrm{CCl}_{4}$ & Animals received $250 \mathrm{mg} / \mathrm{kg}$ b.wt $\mathrm{DRR}$ for 7 days and $1 \mathrm{~mL} / \mathrm{kg}$ b.wt $\mathrm{CCl}_{4}$ on 2 nd and $3 \mathrm{rd}$ days \\
\hline $\mathrm{V}$ & $\mathrm{DRU}+\mathrm{CCl}_{4}$ & Animals received $250 \mathrm{mg} / \mathrm{kg}$ b.wt DRU for 7 days and $1 \mathrm{~mL} / \mathrm{kg}$ b.wt $\mathrm{CCl}_{4}$ on 2 nd and $3 \mathrm{rd}$ days \\
\hline VI & $\mathrm{DRL}+\mathrm{CCl}_{4}$ & Animals received $250 \mathrm{mg} / \mathrm{kg}$ b.wt DRL for 7 days and $1 \mathrm{~mL} / \mathrm{kg}$ b.wt $\mathrm{CCl}_{4}$ on 2 nd and $3 \mathrm{rd}$ days \\
\hline VII & Para only & Animals received $500 \mathrm{mg} / \mathrm{kg}$ b.wt Para (i. p.) daily for 7 days \\
\hline VIII & Sily + Para & Animals orally received $100 \mathrm{mg} / \mathrm{kg}$ b.wt silymarin dissolved in distilled water and $500 \mathrm{mg} / \mathrm{kg}$ b.wt Para (i. p.) \\
\hline IX & $\mathrm{DRR}+$ Para & Animals received $250 \mathrm{mg} / \mathrm{kg}$ b.wt DRR for 7 days and $500 \mathrm{mg} / \mathrm{kg}$ b.wt Para (i. p.) \\
\hline $\mathrm{X}$ & $\mathrm{DRU}+$ Para & Animals received $250 \mathrm{mg} / \mathrm{kg}$ b.wt DRU for 7 days and $500 \mathrm{mg} / \mathrm{kg}$ b.wt Para (i. p.) \\
\hline XI & DRL + Para & Animals received $250 \mathrm{mg} / \mathrm{kg}$ b.wt DRL for 7 days and $500 \mathrm{mg} / \mathrm{kg}$ b.wt Para (i. p.) \\
\hline
\end{tabular}

and VI were pretreated with $250 \mathrm{mg} / \mathrm{kg}$ DRR, DRU, and DRL, respectively, by an oral route, from 1 st to 7 th day.

Similarly, in the Para-induced group, animals in groups VII-XI received acetaminophen $(500 \mathrm{mg} / \mathrm{kg}$ b.wt) suspended in an appropriate volume of distilled water once daily, from 2nd to 7th day. Group VII was maintained on acetaminophen control without drug treatment. Groups IX to XI were pretreated with $250 \mathrm{mg} / \mathrm{kg}$ DRR, DRU, and DRL, respectively, for seven days, while Group XII was treated with $100 \mathrm{mg} / \mathrm{kg}$ silymarin orally, from 1 st to 7 th day. The rats were maintained on a normal diet and water ad libitum. A safe dose of $250 \mathrm{mg} / \mathrm{kg}$ body weight was used based on the safety assessment of leaves [18].

\subsection{Blood Collection and Assessment of Hepatoprotective} Activity. At the end of the experimental period, all the animals were sacrificed after an overnight fast on the 7 th day by cervical dislocation. Blood samples were collected into gel-activated tubes via an incision in the cervical region with the aid of a sterile blade for biochemical assays. The following biochemical parameters, alanine aminotransferase (ALT), aspartate aminotransferase (AST), alkaline phosphatase (ALP), gamma-glutamyl transferase $(\gamma \mathrm{GT})$, bilirubin (total and direct), total protein, albumin, total cholesterol, triglycerides, urea, and creatinine, were determined using the Selectra E (Vital Scientific, Japan) autoanalyzer.

2.6. Determination of Relative Organ Weight (ROW). Excised liver of rats was washed in buffered normal saline and weighed to obtain the absolute liver weights (ALW). The relative organ weights (RLW) were calculated using the following formula:

Relative liver weight weight $=\frac{\text { Absolute liver weight }}{\text { Body weight at sacrifice }} \times 100$.

2.7. Effect of Treatment of Oxidative Stress Parameters. Liver tissues $(1 \mathrm{~g})$ were homogenised in $10 \mathrm{~mL}$ of $100 \mathrm{mM}$ $\mathrm{KH}_{2} \mathrm{PO}_{4}$ buffer containing $1 \mathrm{mM}$ EDTA, $\mathrm{pH}$ 7.4, and centrifuged at $12,000 \mathrm{rpm}$ for $30 \mathrm{~min}$ at $4^{\circ} \mathrm{C}$. The supernatant was collected and used for the determination of nitric oxide (NO) [19], hydrogen peroxide $\left(\mathrm{H}_{2} \mathrm{O}_{2}\right)$ [20], malondialdehyde (MDA) [21], reduced glutathione (GSH) [22], superoxide dismutase (SOD) $[23,24]$, and glutathione peroxidase (GPx) [25].

2.8. Histology. Liver sections of the right lobes were preserved in $10 \%$ buffered formalin for fixation. Sections of $5-6 \mu \mathrm{m}$ in thickness were made and stained with haematoxylin and eosin for histological examination by pathologists.

2.9. Statistical Analysis. Results were analysed using GraphPad Prism 8.0 (GraphPad Software Inc., USA) for Windows. Experimental values were expressed as mean \pm standard error of the mean (SEM). Data were assessed by ANOVA followed by Tukey's multiple comparison test to evaluate the significance between the various group. A $p$-value $\leq 0.05$ was considered as significant.

Percentage protection was calculated based on the principal indicators of liver protection (AST, ALT, ALP, $\gamma \mathrm{GT}$, TBIL, DBIL, and IBIL) using the following formula:

$$
\begin{aligned}
\% \text { protection }= & \frac{\text { Value of toxin control }- \text { Value of test sample }}{\text { Value of toxin control }- \text { Value of normal control }} \\
& \times 100 .
\end{aligned}
$$

\section{Results}

3.1. Effect of Treatment on Absolute and Relative Liver Weights. The intoxication with $\mathrm{CCl}_{4}$ and acetaminophen resulted in significant increases in the absolute liver weights $(P<0.001)$. Treatment with silymarin, DRR, DRU, and DRL reversed the trend (Figure 1). No significant changes were observed in the relative liver weights.

3.2. Effect of Treatment on Biochemical Parameters. The administration of $\mathrm{CCl}_{4}$ and acetaminophen caused significant increases $(p<0.05-0.01)$ in ALT, AST, ALP, $\gamma \mathrm{GT}$, and 


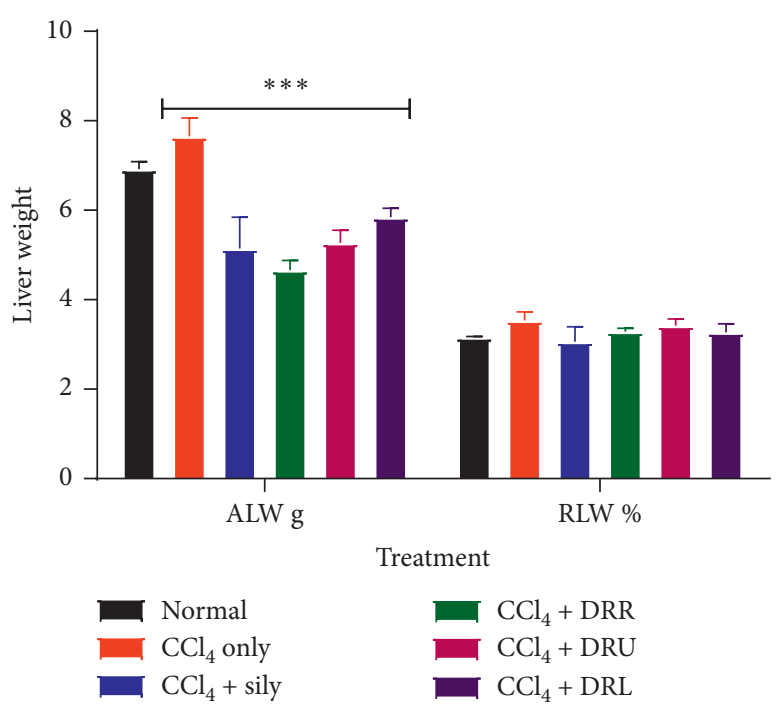

(a)

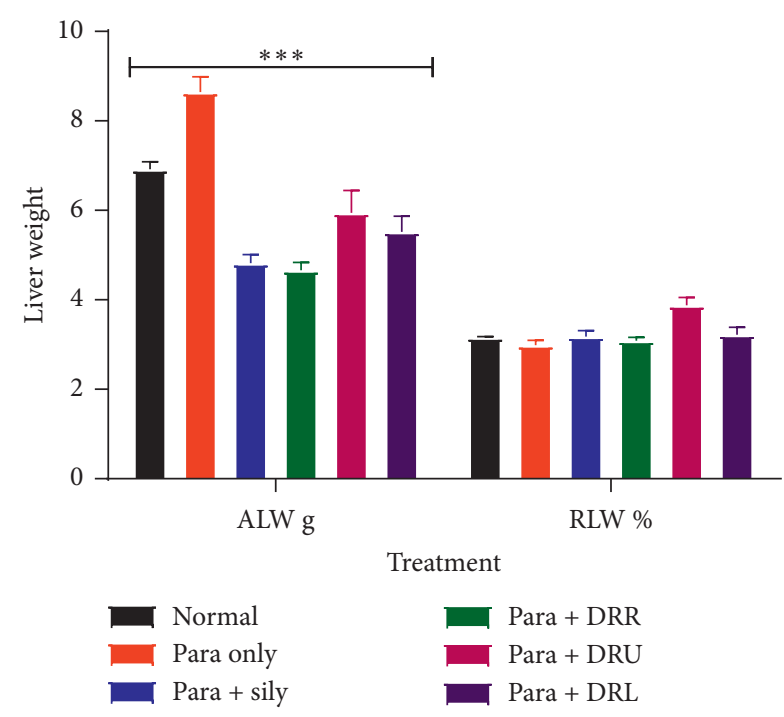

(b)

FIgURE 1: Effects of silymarin, DRR, DRU, and DRL on the absolute and relative liver weight of animals. ${ }^{* * *} P<0.001$ from normal.

TBil compared with the normal. Pretreatment with silymarin and extracts of $D$. erecta parts resulted in decreases in these parameters to near-normal levels when compared with $\mathrm{CCl}_{4}$ and Para only treated groups (Table 2).

3.3. Percentage Protection. The percentage protection of $100 \mathrm{mg} / \mathrm{kg}$ silymarin, DRL, DRR, and DRU at $250 \mathrm{mg} / \mathrm{kg}$ against $\mathrm{CCl}_{4}$ and acetaminophen is as shown in Figure 2. This was calculated as a function of principal indicators of liver function including ALT, AST, ALP, $\gamma \mathrm{GT}$, and TBil. Silymarin and DRR at $250 \mathrm{mg} / \mathrm{kg}$ b.wt exhibited the highest percent protection against $\mathrm{CCl}_{4}$ and Para. Thus, the liver samples of these groups were subjected to histological, enzymatic, and nonenzymatic pro- and antioxidant assays. All extracts, however, offered some level of liver protection.

3.4. Effect of Treatment on the Antioxidant Defence System. The effect of treatments on oxidative stress parameters was assessed on silymarin- and DRR-treated groups since they showed the highest protection. Administration of $\mathrm{CCl}_{4}$ caused significant increases $(p<0.001)$ in $\mathrm{H}_{2} \mathrm{O}_{2}, \mathrm{MDA}$, and NO levels, and a decrease in the GPx level compared with normal control while Para-only treatment resulted in similar observations except for $\mathrm{NO}$ levels. DRR cotreated with $\mathrm{CCl}_{4}$ resulted in decreases in $\mathrm{H}_{2} \mathrm{O}_{2}$ and MDA levels and increases in GPx, SOD, and $\mathrm{NO}$ compared with $\mathrm{CCl}_{4}$ only and Para only control groups. Silymarin cotreatments resulted in decreases in $\mathrm{H}_{2} \mathrm{O}_{2}$ and MDA levels with increases in GPx and SOD against Para while decreases in NO and MDA levels and increases in GPx and SOD were observed against $\mathrm{CCl}_{4}$ only control group (Table 3).

3.5. Effect of Treatment on Liver Histology. The histological observations of the normal group revealed no observable lesions (Figure 3(a)). However, animals treated with $\mathrm{CCl}_{4}$ only showed hepatocellular atrophy and coagulation necrosis of hepatocytes with some inflammatory cells (Figure 3(b) ). Paracetamol-only treatment resulted in the development of moderate centrilobular hepatocellular and cord atrophy (Figure 3(e)). Pretreatment with silymarin (Figures 3(c) and 3(f)) showed no observable lesions to moderate centrilobular hepatocellular vascular degeneration and a few regenerative hepatocytes. Cotreatment with DRR (Figures 3(d) and 3(g)) attenuated the changes associated with $\mathrm{CCl}_{4^{-}}$and Para-induced liver damage (Figure 3) with no observable damage to moderate diffuse hepatocellular atrophy and perivascular infiltrates in the portal tract. Table 4 shows the lesion scores for the liver of normal and treated groups.

\section{Discussion}

Liver diseases are serious ailments claiming the lives of more than 2 million people globally in a year [26]. Despite recent advances in orthodox medicine, effective hepatoprotective medicine with low or no side effects is not easily available. Exposure of liver cells to toxicants is one of the ways to develop hepatoprotective drugs. In this present study, the effect of hydroethanolic extract of Duranta erecta was evaluated against $\mathrm{CCl}_{4^{-}}$and acetaminophen-induced liver damage. These hepatotoxicants exert their deliberating effects through their active metabolites.

Changes in organ weight have been used as good indicators to evaluate the toxic effect of the test substance [27]. Alterations in organ weight may not directly reflect its functional state. Organ toxicity happens when there are changes in cellular structure or functions even after administration and elimination of the causative agent [28]. The observed significant increase in absolute liver weight after the administration of $\mathrm{CCl}_{4}$ and acetaminophen may be the result of direct toxicity of these hepatotoxicants and/or indirect toxicity leading to hypertrophy and liver damage 


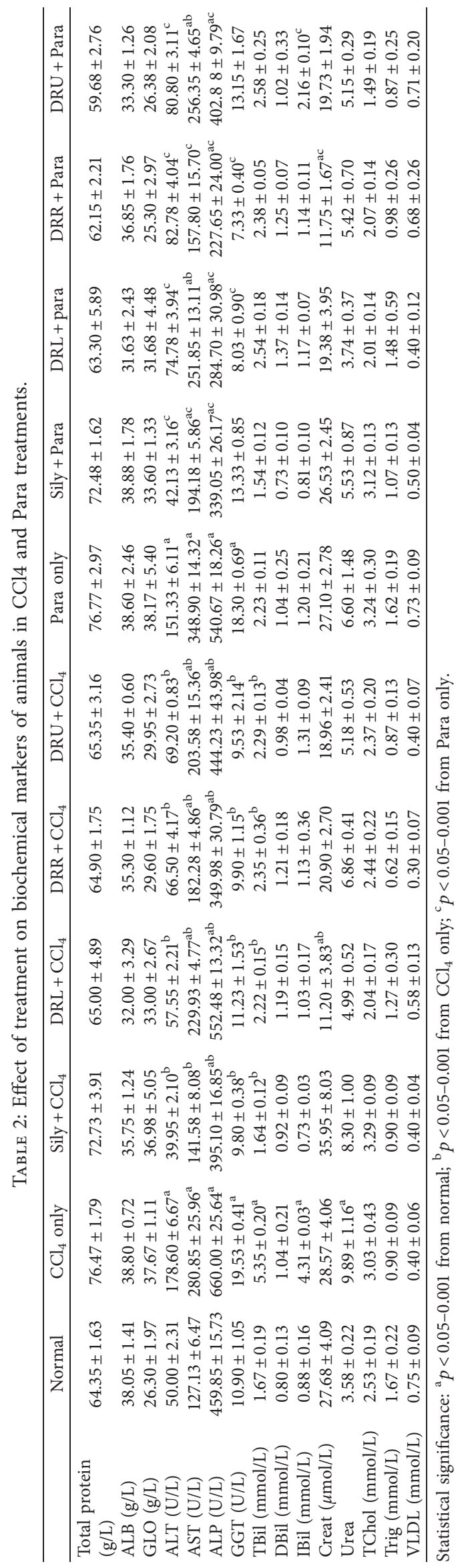




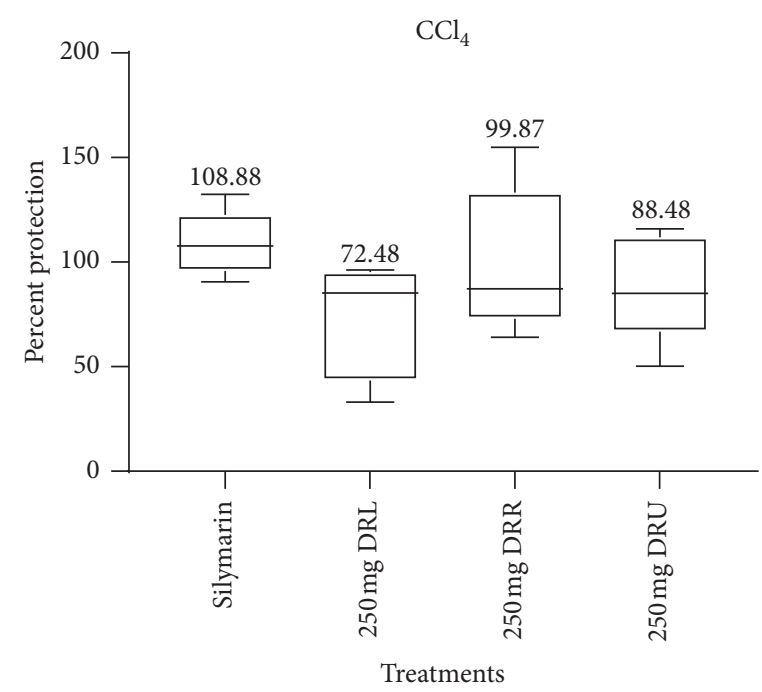

(a)

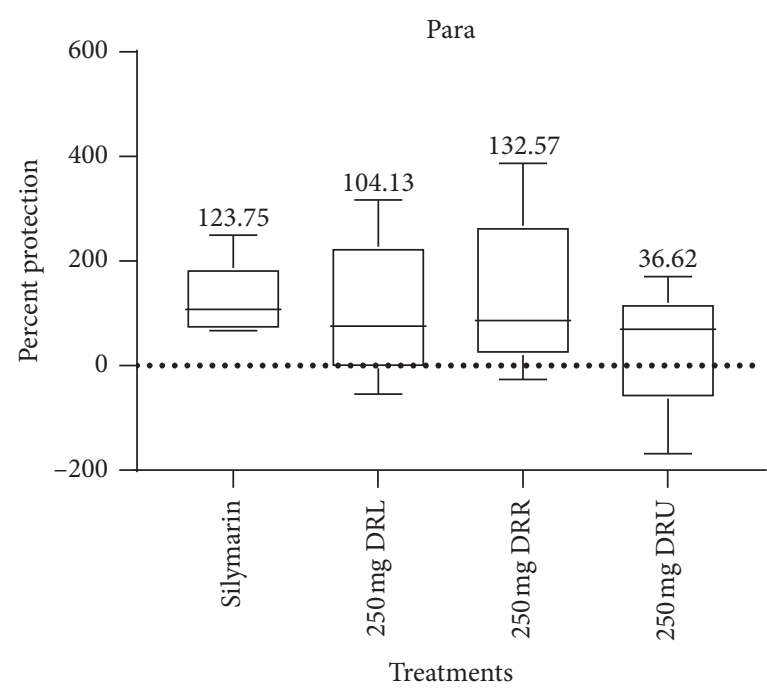

(b)

FIGURE 2: Percentage protection of silymarin and the extracts of D. erecta against $\mathrm{CCl}_{4}$ and acetaminophen.

TABLE 3: Effect of treatment on liver oxidative stress parameters.

\begin{tabular}{|c|c|c|c|c|c|c|c|}
\hline & Normal & $\mathrm{CCl}_{4}$ only & Para only & $\mathrm{CCl}_{4}+$ Sily & Para + Sily & $\mathrm{CCl}_{4}+\mathrm{DRR}$ & Para + DRR \\
\hline $\begin{array}{l}\mathrm{H}_{2} \mathrm{O}_{2}(\mu \mathrm{mole} / \mathrm{mg} \\
\text { protein })\end{array}$ & $69.78 \pm 6.74$ & $99.06 \pm 10.63^{a}$ & $122.31 \pm 17.37^{\mathrm{a}}$ & $110.17 \pm 8.07^{\mathrm{a}}$ & $56.13 \pm 3.13^{c}$ & $65.58 \pm 6.97^{\mathrm{b}}$ & $121.63 \pm 16.79^{\mathrm{a}}$ \\
\hline $\begin{array}{l}\text { MDA ( } \mu \text { mole/mg } \\
\text { protein) }\end{array}$ & $3.59 \pm 0.68$ & & & & & & \\
\hline $\begin{array}{l}\text { GSH }(\mu \text { mole } / \mathrm{mg} \\
\text { protein })\end{array}$ & $74.72 \pm 2.34$ & & & & & & $74.82 \pm 2.27$ \\
\hline $\begin{array}{l}\text { GPx }(\mu \mathrm{mole} / \mathrm{mg} \\
\text { protein })\end{array}$ & $713.82 \pm 48.18$ & $563.03 \pm 24.57^{\mathrm{a}}$ & $682.95 \pm 49.60$ & & $1225.42 \pm 37.90^{c}$ & $906.05 \pm 65.94^{\mathrm{ab}}$ & $1055.99 \pm 42.72^{\mathrm{ac}}$ \\
\hline $\begin{array}{l}\mathrm{GST}(\mu \mathrm{mole} / \mathrm{min} / \\
\text { mg protein) }\end{array}$ & $1.07 \pm 0.11$ & $0.78 \pm 0.12$ & $1.22 \pm 0.18$ & $0.90 \pm 0.19$ & $0.91 \pm 0.22$ & $2.14 \pm 1.0$ & $2.63 \pm 0.68$ \\
\hline $\begin{array}{l}\text { SOD (Units/mg } \\
\text { protein) }\end{array}$ & $25.28 \pm 1.70$ & $19.94 \pm 0.84$ & $25.83 \pm 2.38$ & $31.75 \pm 2.48^{\mathrm{b}}$ & $43.88 \pm 1.31^{\mathrm{ac}}$ & $32.60 \pm 2.47^{\mathrm{b}}$ & $37.51 \pm 1.05^{\mathrm{ac}}$ \\
\hline $\begin{array}{l}\text { Nitric oxide } \\
(\mu \mathrm{mole} / \mathrm{L})\end{array}$ & $0.98 \pm 0.05$ & $2.77 \pm 0.47^{\mathrm{a}}$ & $0.98 \pm 0.03$ & $1.19 \pm 0.16^{\mathrm{b}}$ & $0.49 \pm 0.02$ & $2.14 \pm 0.16^{\mathrm{a}}$ & $2.53 \pm 0.17^{\mathrm{ac}}$ \\
\hline
\end{tabular}

Statistical Significance: ${ }^{\mathrm{a}} p<0.05-0.001$ from normal; ${ }^{\mathrm{b}} p<0.05-0.001$ from $\mathrm{CCl}_{4}$ only; ${ }^{\mathrm{c}} p<0.05-0.001$ from Para only.

(Figure 1). Pretreatment of animals with silymarin, DRR, DRU, and DRL decreased the absolute liver weights of treated animals compared to the hepatotoxin only group, indicating the ameliorative effect of the extracts.

Estimation of the activity of liver enzymes, namely, AST, ALT, ALP, and GGT in the event of hepatic injury is one of the useful tools in the study of hepatotoxicity as it can unfold the extent and type of damage $[29,30]$. Serum AST and ALT are the cardinal indicators of liver injury, although ALT is a more selectively liver parenchymal enzyme than AST, whereas ALP is often used as an indicator of liver and gallbladder diseases [31]. Elevated serum GGT level has been associated with liver diseases and nonhepatic diseases, including chronic obstructive pulmonary disease. In $\mathrm{CCl}_{4}$ - and acetaminophen-induced hepatotoxicity, the levels of liver enzymes in the bloodstream were affected and these reflect the status of liver function. The increased activities of these enzymes following the administration of the hepatotoxicants may be interpreted as hepatocyte damage and alterations in the membrane permeability. These findings are in agreement with previous studies $[4,6]$. Pretreatment with the extracts and silymarin resulted in decreases of these parameters to near-normal levels in both $\mathrm{CC}_{4}$ - and acetaminophen-induced damage, suggesting that extracts are beneficial in attenuating liver injury.

Bilirubin is a by-product of the breakdown of red blood cells in the liver. Accumulation, binding, conjugation, and excretion of bilirubin are related to the integrity and function of the liver. The increased serum total bilirubin level in the $\mathrm{CCl}_{4}$ - and acetaminophen-treated rats observed in this study may be attributed to the failed processing capacity of the hepatocytes [32] which is a common feature of liver injury. However, the current results indicated that cotreatment with extracts were more effective in reversing the anomalies observed. Serum total protein level may indicate the state and type of damage to the liver [33]. Severe 


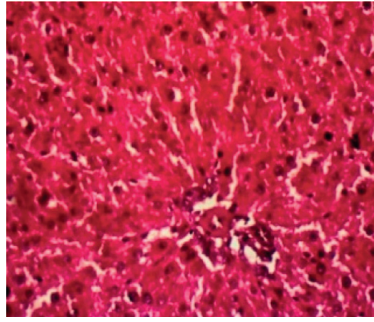

(a)

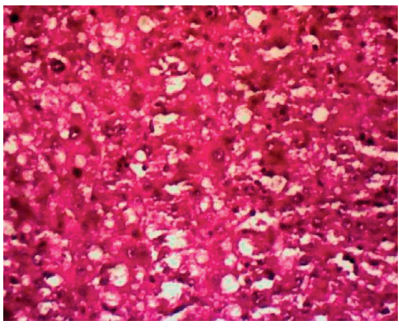

(b)

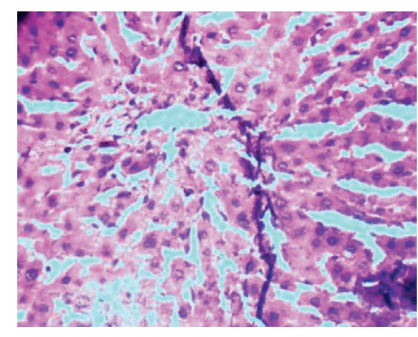

(c)

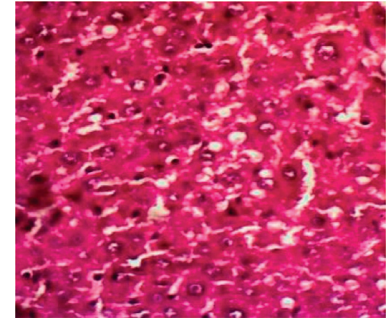

(d)

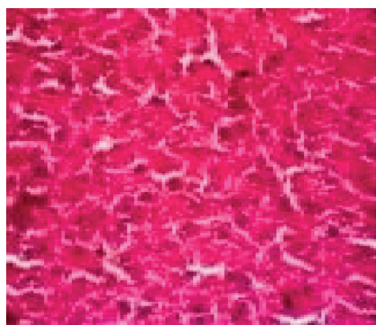

(e)

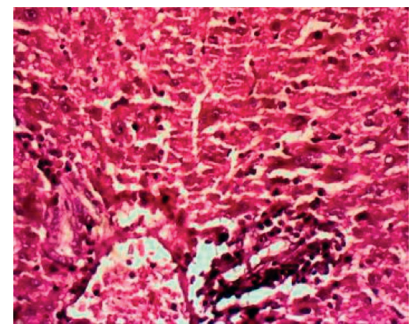

(f)

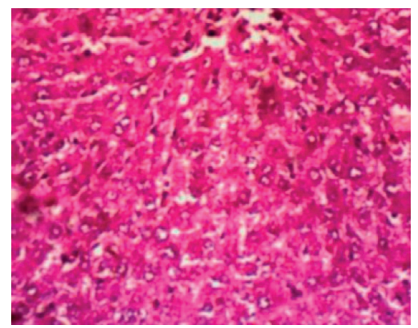

(g)

FIgURE 3: Photomicrographs showing liver of rats. (a) Normal-the hepatocytes are normal morphologically and arranged in cords around blood vessels except that the limiting plate appears shrunken, (b) $\mathrm{CCl}_{4}$ only-centrilobular coagulation necrosis of hepatocytes, (c) $\mathrm{CCl}_{4}+$ Sily-moderate centrilobular hepatocellular vascular degeneration, restricted more to the zone 3 hepatocytes and a few regenerative hepatocytes, (d) $\mathrm{CCl}_{4}+$ DRR-diffuse hepatocellular atrophy, spotty hepatocellular necrosis, Kupffer cell hyperplasia, and moderate perivascular infiltrates in the portal tract, (e) Para only: Moderate centrilobular hepatocellular and cord atrophy, (f) Para + Sily: normal (no observable lesion), and (g) Para + DRR: LIVER- normal (no observable lesion).

TABLE 4: Scoring of lesions.

\begin{tabular}{lcc}
\hline Group & Score & Lesion \\
\hline Normal & 0 & No observable lesion \\
$\mathrm{CCl}_{4}$ & 4 & Hepatocellular atrophy and coagulation necrosis of hepatocytes with some inflammatory cells \\
Para only & 2 & Moderate centrilobular hepatocellular and cord atrophy \\
$\mathrm{CCl}_{4}+$ Sily & 2 & Moderate centrilobular hepatocellular degeneration and a few regenerative hepatocytes \\
Para + Sily & 0 & No observable lesion \\
DRR $+\mathrm{CCl}_{4}$ & 3 & Diffused vacuolar degeneration, Kupffer cell hyperplasia, moderate perivascular infiltrates in portal tract \\
DRR + Para & 0 & No observable lesion \\
\hline
\end{tabular}

liver damage usually leads to decreased production of various proteins, resulting in reduced serum levels of total protein, albumin, and globulins. However, in the current study, no significant changes were observed due to the acute nature of the study.

Comparatively, the hepatoprotective potentials of DRR, DRU, DRL, and silymarin against $\mathrm{CCl}_{4}$ and acetaminophen showed that $250 \mathrm{mg} / \mathrm{kg}$ b.wt of DRR offered a better protective effect against $\mathrm{CCl}_{4}$ - and paracetamol-induced toxicity after silymarin (Figure 2). The high protective effect of DRR and DRL could be attributed to the presence of phenols in the extracts as well as the free radical scavenging effect [8] which can deplete free radicals generated by the metabolism of $\mathrm{CCl}_{4}$ and acetaminophen.

Creatinine is a breakdown product in the muscle by creatine phosphate metabolism. Urea is the main product of protein catabolism. Creatinine and urea are important biochemical parameters for the diagnosis of renal impairment. Although $\mathrm{CCl}_{4}$ and Para treatments only did not result in elevations in these parameters, DRL, DRR, and DRU cotreatments resulted in significant decreases, signifying a possible nephroprotective potential attributable to the antioxidant and free radical scavenging properties of the extracts [8].

Free radicals produced by acetaminophen and $\mathrm{CCl}_{4}$ exert their deleterious effect on the liver through inflammatory response and oxidative stress, leading to initiation and progression of hepatic damage [35]. The mechanism of $\mathrm{CCl}_{4}$ injury results from its bioactivation to trichloromethyl peroxyl radical in the presence of oxygen by cytochrome P-450 enzymes, leading to peroxidation of lipids, covalent binding of macromolecules, disruption of metabolic mechanisms in mitochondria, inhibition of calcium pumps of microsomes, and secondary damage from an inflammatory process $[36,37]$. The toxicity of acetaminophen is attributed to its highly reactive metabolite $\mathrm{N}$-acetyl-p-benzoquinoneimine (NAPQI) which is activated by cytochrome P-450. NAPQI reacts with glutathione $(\mathrm{GSH})$ causing its depletion to form protein adducts. This leads to mitochondrial dysfunction with its associated ATP depletion and 
oxidation stress which are thought to be critical for liver damage $[34,38]$. Nature has an effective mechanism to prevent and neutralize the free radical-induced damage by employing an array of nonenzymatic and enzymatic reaction pathways.

MDA is a direct biochemical indicator for oxidative stress, and its elevation is an indication of an increased lipid peroxidation due to the production of superoxide, peroxyl, and hydroxyl radicals [39]. Increased MDA level, as evidenced in $\mathrm{CCl}_{4}$ and acetaminophen treated groups, is suggestive of enhanced lipid peroxidation and failure of antioxidant defence mechanisms to prevent the formation of excessive free radicals. The administration of the toxicants results in their active metabolites binding with cell protein, leading to lipid peroxidation of the cell membrane and endoplasmic reticulum, which in turn gives products like MDA. Current results suggested that the treatment with DRR caused a significant decrease in the levels of MDA through attenuation of lipid peroxidation and decreased production of free radical derivatives. This result indicates the hepatoprotective efficacy of the extract. This could be attributed to the antioxidant effect of the extract scavenging the free radicals, supplying a competitive substrate for unsaturated lipids in the membrane, and/or accelerating the repair mechanism of the damaged cell membrane [40].

$\mathrm{H}_{2} \mathrm{O}_{2}$ is produced in cells by a dismutation of superoxide radicals generated in the oxidative process by SOD [41]. It produces cytotoxicity in the endothelial cells of different organs [42]. Significantly elevated levels of $\mathrm{H}_{2} \mathrm{O}_{2}$ generation observed in acetaminophen- and $\mathrm{CCl}_{4}$-administered rats (Table 3 ) indicate the excessive formation of free radicals, resulting in hepatic damage. Pretreatment with DRR reversed these changes through the attenuation of lipid peroxidation and decreased the production of free radical derivatives as corroborated by a decreased level of MDA.

Nitric oxide (NO) is a vasodilator produced by endothelial nitrous oxide (NOS) which plays a critical role in the regulation of vascular tone by several mechanisms [43]. Low level of NO elicits hypertension, whereas excessive production could also precipitate hypotension. NO reacts with the superoxide radical to form the more potent oxidant peroxynitrite which is a highly toxic species and reacts with $\mathrm{GSH}$, lipids, proteins, and DNA. The administration of $\mathrm{CCl}_{4}$ resulted in a significant increase $(p<0.001)$ of NO level, an indication of nitrosative stress. Pretreatment with the DRR reversed the change through attenuation of reactive nitrogen species. The ability of the extract to down regulate the level of radicals is an indication of its hepatoprotective protentials.

The body employs a set of endogenous antioxidant enzymes, such as SOD, GPx, and GST, as a defence mechanism to neutralise free radical-induced damage. SOD is a group of metalloenzymes which protects cells from the toxic effects of the endogenously generated superoxide radicals [44]. It is the first line of defence against free radical generation. SOD dismutates superoxide anion radical to $\mathrm{H}_{2} \mathrm{O}_{2}$ which can be rapidly converted to $\mathrm{H}_{2} \mathrm{O}$ and $\mathrm{O}_{2}$ by GPx [45]. GST is responsible for the detoxification of xenobiotics and takes part in maintaining glutathione homeostasis [24]. GSH is a multifunctional thiol-containing intracellular, nonenzymatic antioxidant. It is involved in the protection of the thiol group of proteins from oxidation by free radicals [46] and it acts as a substrate for GPx and GST. GPx and GST as antioxidant enzymes work together with GSH to decompose of $\mathrm{H}_{2} \mathrm{O}_{2}$ and other organic hydroperoxides [47]. Results of current studies indicated that the intoxication of the rats with the $\mathrm{CCl}_{4}$ significantly reduced the GPx level, compared with the control (Table 3) which was in line with other findings [48]. The decreased level of GPx and other antioxidant enzymes is most likely due to the overproduction of free radicals through oxidative stress that overwhelmed the antioxidant defence system. Pretreatment with DRR reversed these changes, resulting in upregulation in the activity of antioxidant enzyme and GPx which may suggest the development of an adaptive response to rid the body of oxidative stress. The observed modulation of oxidative stress by the hydroethanolic extracts of plant parts can be attributed to the reported in vitro antioxidant activities reported for Ghanaian [8], Nigerian [49], and Egyptian [50] cultivars. Furthermore, observations of the current study lay credence to the medicinal properties of ornament plants including hepatoprotection as previously reported for Tecoma stans L. [51] and other species.

The histological observation of the liver sections revealed hepatocellular atrophy and coagulation necrosis of hepatocytes with some inflammatory cells in the $\mathrm{CCl}_{4}$-induced damage whilst moderate centrilobular hepatocellular and cord atrophy was recorded in acetaminophen-induced rats. This could be due to the formation of the highly reactive metabolites of the various hepatotoxicants. The administration of DRR and silymarin resulted in no observable lesion in the acetaminophen-induced group which was close to normal cellular architecture and diffused vacuolar degeneration, Kupffer cell hyperplasia, and moderate perivascular infiltrates in the portal tract in the $\mathrm{CCl}_{4}$-induced rats (Figure 3, Table 4). These results are consistent with the various biochemical parameters that proved the hepatoprotective efficacy of the plant.

\section{Conclusion}

Based on the results obtained in this study, it is concluded that the extracts of Duranta erecta particularly the leaves and ripe fruits exhibit a strong protective effect against $\mathrm{CCl}_{4}$ - and acetaminophen-induced liver injury by modulating serum and liver biochemical parameters, supported by histological observation. Thus, 50\% hydroethanolic ripped fruit extract of $D$. erecta is hepatoprotective by inhibition of oxidative stress and improvement in liver microarchitecture and function attributable to its phytochemical constituents and can be exploited as a therapeutic agent against acute liver diseases.

\section{Data Availability}

The data used and/or analysed during the current study are available from the corresponding author upon request. 


\section{Ethical Approval}

All animals were humanely treated following standard International protocols.

\section{Conflicts of Interest}

The authors declare that there are no conflicts of interest.

\section{References}

[1] P. Byass, "The global burden of liver disease: a challenge for methods and for public health," BMC Medicine, vol. 12, no. 1, p. 159, 2014.

[2] WHO, "World health rankings; Ghana-liber disease," 2018, https://www.worldlifeexpectancy.com/ghana-liver-disease.

[3] T. Prakash, S. D. Fadadu, U. R. Sharma et al., "Hepatoprotective activity of leaves of Rhododendron arboreum in $\mathrm{CCl}_{4}$ induced hepatotoxicity in rats," Journal of Medicinal Plant Research, vol. 2, pp. 315-320, 2008.

[4] F. K. N. Arthur, E. Woode, E. O. Terlabi, and C. Larbie, "Evaluation of hepatoprotective effect of aqueous extract of Annona muricata (Linn.) leaf against carbon tetrachloride and acetaminophen-induced liver damage," Journal of Natural Pharmaceuticals, vol. 3, no. 1, pp. 25-30, 2012.

[5] F. Sarfo-Antwi, C. Larbie, and D. Babatunde, "Extracts of Ageratum conyzoides L. protects against carbon tetrachloride-induced toxicity in rats through inhibiting oxidative stress," Journal of Advances in Medical and Pharmaceutical Sciences, vol. 19, no. 2, pp. 1-14, 2018.

[6] A. K. A. Genfi, C. Larbie, E. O. Emikpe, A. A. Oyagbemi, C. K. Firempong, and C. O. Adjei, "Modulation of oxidative stress and inflammatory cytokines as therapeutic mechanisms of Ocimum americanum extract in carbon tetrachloride and acetaminophen-induced toxicity in rats," Journal of EvidenceBased Integrative Medicine, vol. 25, pp. 1-13, 2020.

[7] A. S. Ogbuagu, K. Okoro, M. U. Akpuaka, J. O. Ogbuagu, U. E. Ekpunobi, and E. C. Ohaekenyem, "Quantitative determination of some secondary metabolites and the antibacterial effects of the leave extracts of Duranta eracta," American Journal of Biomedical Science and Engineering, vol. 1, pp. 82-87, 2015.

[8] S. Donkor, C. Larbie, G. KomLaga, Benjamin, and B. O. Emikpe, "Phytochemical, antimicrobial, and antioxidant profiles of Duranta erecta L. Parts," Biochemistry Research International, vol. 2019, Article ID 8731595, 11 pages, 2019.

[9] M. Sikarwar, S. A. Ganie, R. K. Agnihotri, and R. Sharma, "Evaluation of Duranta repens for its antifungal potential," International Journal of Medicinal Plants, vol. 106, pp. 390$395,2014$.

[10] F. Ijaz, N. Ahmad, I. Ahmad, A. Ul Haq, and F. Wang, "Two new anti-plasmodial flavonoid glycosides from Duranta repens," Journal of Enzyme Inhibition and Medicinal Chemistry, vol. 25, no. 6, pp. 773-778, 2010.

[11] L. M. Abou-Setta, N. M. Nazif, and A. A. Shahat, "Phytochemical investigation and antiviral activity of Duranta repens," Journal of Applied Sciences Research, vol. 3, pp. 1426-1433, 2007.

[12] A. V. Puri, "Duranta repens Linn. (Verbenaceae): a comprehensive review of pharmacognostic, ethnomedicinal, pharmacological, and phytochemical aspects," Asian Journal of Pharmaceutical and Clinical Research, vol. 11, no. 11, pp. 91-96, 2018.
[13] R. Subsongsang and W. Jiraungkoorskul, “An updated review on phytochemical properties of "golden dewdrop" Duranta erecta," Pharmacognosy Reviews, vol. 10, no. 20, pp. 115-117, 2016.

[14] M. A. Abd El-Ghany, "Nutraceutical effects of garlic, olive, parsley and menthe oils on $\mathrm{CCl}_{4}$ induced liver damage in rats," Egyptian Journal of Nutrition, vol. 21, no. 4, pp. 125-159, 2006.

[15] J. A. Hinson, D. W. Roberts, and L. P. James, "Mechanisms of acetaminophen-induced liver necrosis," Handbook of Experimental Pharmacology, vol. 196, pp. 369-405, 2010.

[16] K. Bhar, L. K. Kantha, S. Manna, P. Nagalaxmi, K. Eswar, and C. Satya, In-vitro cytotoxic activity and anthelmintic activity of chloroform extract of D. erecta L. ripe fruits," Research Journal of Pharmaceutical, Biological and Chemical Sciences, vol. 7, no. 6, pp. 860-865, 2016.

[17] National Research Council, Guide for Care and Use of Laboratory Animalpp. 43-45, National Academic Press, Washington D.C, USA, 8th edition, 2011.

[18] S. Donkor, C. Larbie, G. KomLaga, and B. O. Emikpe, "Toxicity of the hydroethanolic leaves extract of Duranta erecta L. in rat models," Journal of Pharmaceutical Research International, vol. 32, no. 6, pp. 9-18, 2020.

[19] S. B. Olaleye, O. A. Adaramoye, P. P. Erigbali, and O. S. Adeniyi, "Lead exposure increases oxidative stress in the gastric mucosa of $\mathrm{HCl} /$ ethanol-exposed rats," World Journal of Gastroenterology, vol. 13, no. 38, pp. 5121-5126, 2007.

[20] S. P. Woff, "Ferrous ion oxidation in the presence of ferric ion indicator xylenol orange for measurement of hydroperoxides," Methods in Enzymology, vol. 233, pp. 182-189, 1994.

[21] E. O. Farombi, J. G. Tahnteng, A. O. Agboola, J. O. Nwankwo, and G. O. Emerole, "Chemoprevention of 2-acetylaminofluorene-induced hepatotoxicity and lipid peroxidation in rats by kolaviron-a Garcinia kola seed extract," Food and Chemical Toxicology, vol. 38, no. 6, pp. 353-341, 2000.

[22] D. J. Jollow, J. R. Mitchell, N. Zampaglione, and J. R. Gillette, "Bromobenzene-induced liver necrosis. Protective role of glutathione and evidence for 3,4-bromobenzene oxide as the hepatotoxic metabolite," Pharmacology, vol. 11, no. 3, pp. 151-169, 1974.

[23] H. P. Misra and I. Fridovich, "The role of superoxide anoin in the autoxidation of epinephrine and a simple assay for superoxide dismutase," Journal of Biological Chemistry, vol. 247, no. 10 , pp. $3170-3175,1972$.

[24] A. A. Oyagbemi, T. O. Omobowale, A. S. Akinrinde, A. B. Saba, B. S. Ogunpolu, and O. Daramola, "Lack of reversal of oxidative damage in renal tissues of lead acetate-treated rats," Environmental Toxicology, vol. 30, no. 11, pp. 1235-1243, 2015.

[25] E. Buetler, O. Duron, and B. M. Kelly, "Improved method for the determination of blood glutathione," Journal of Laboratory and Clinical Medicine, vol. 61, pp. 882-888, 1963.

[26] S. K. Asrani, H. Devarbhavi, J. Eaton, and P. S. Kamath, "Burden of liver diseases in the world," Journal of Hepatology, vol. 70, no. 1, pp. 151-171, 2019.

[27] Y. Piao, Y. Liu, and X. Xie, "Change trends of organ weight background data in Sprague Dawley rats at different ages," Journal of Toxicologic Pathology, vol. 26, no. 1, pp. 29-34, 2013.

[28] E. D. Kharasch, "Complications in anesthesia," in Volatile Anesthetics: Organ Toxicity, pp. 66-68, The publishers are W.D. Sanders, Philadelphia, PA, USA, 2nd edition, 2007.

[29] S. K. Ramaiah, "A toxicologist guide to the diagnostic interpretation of hepatic biochemical parameters," Food and Chemical Toxicology, vol. 45, no. 9, pp. 1551-1557, 2007. 
[30] S. Priya and S. Nethaji, "Hepatoprotective activity of ethanolic extract of Diospyros virginiana in $\mathrm{CCl}_{4}$ induced hepatotoxicity in swiss albino rats," International Journal of Pharm Tech Research, vol. 8, no. 3, pp. 444-447, 2015.

[31] E. Pavan, A. S. Damazo, L. M. S. Lemos et al., "Evaluation of genotoxicity and subchronic toxicity of the standardized leaves infusion extract of copaifera malmei harms in experimental models," Journal of Ethnopharmacology, vol. 211, pp. 70-77, 2018.

[32] K. Singh, N. Singh, A. Chandy, and A. Manigauha, "In vivo antioxidant and hepatoprotective activity of methanolic extracts of daucus carota seeds in experimental animals," Asian Pacific Journal of Tropical Biomedicine, vol. 2, no. 5, pp. 385-388, 2012.

[33] S. Sabiu, A. M. Wudil, and T. O. Sunmonu, "Combined administration of Telfairia occidentalis and Vernonia amygdalina leaf powders ameliorates garlic-induced hepatotoxicity in wistar rats," Pharmacologia, vol. 5, no. 5, pp. 191-198, 2014.

[34] H. Jaeschke, "Reactive oxygen and mechanisms of inflammatory liver injury: present concepts," Journal of Gastroenterology and Hepatology, vol. 26, no. Suppl 1, pp. 173-179, 2011.

[35] S. Li, M. Hong, H.-Y. Tan, N. Wang, and Y. Feng, "Insights into the role and interdependence of oxidative stress and inflammation in liver diseases," Oxidative Medicine and Cellular Longevity, vol. 2016, pp. 1-21, Article ID 4234061, 2016.

[36] V. M. Chandrashekhar, A. A. Muchandi, S. V. Sudi, and S. Ganapty, "Hepatoprotective activity of Stereospermum suaveolen sagainst $\mathrm{CCl}_{4}$-induced liver damage in albino rats," Pharmaceutical Biology, vol. 48, no. 5, pp. 524-528, 2010.

[37] K. S. Nelson, R. K. Reddy, C. B. K. Sekhar, and C. R. Das, "Hepatoprotective effect of Cleome gynandra on carbon tetrachloride induced hepatotoxicity in wistar rats," American Journal of Advanced Drug Delivery, vol. 6, pp. 734-740, 2014.

[38] A. Ramachandran and H. Jaeschke, "Mechanisms of acetaminophen hepatotoxicity and their translation to the human pathophysiology," Journal of Clinical and Translational Research, vol. 3, no. Suppl 1, pp. 157-169, 2017.

[39] M. A. Abdel-Wahhab, S. H. Abdel-Azim, and A. A. ElNekeety, "Inula crithmoides extract protects against ochratoxin A-induced oxidative stress, clastogenic and mutagenic alterations in male rats," Toxicon, vol. 52, no. 4, pp. 566-573, 2008.

[40] J. Jodynis-Liebert, T. Adamska, M. Ewertowska, W. Bylka, and I. Matławska, "Aquilegia vulgaris extract attenuates carbon tetrachloride-induced liver fibrosis in rats," Experimental and Toxicologic Pathology, vol. 61, no. 5, pp. 443-451, 2009.

[41] A. K. Dixit, D. Bhatnagar, V. Kumar, D. Chawla, K. Fakhruddin, and D. Bhatnagar, "Antioxidant potential and radioprotective effect of soy isoflavone against gamma irradiation induced oxidative stress," Journal of Functional Foods, vol. 4, no. 1, pp. 197-206, 2012.

[42] T. O. Omobowale, A. A. Oyagbemi, A. S. Akinrinde et al., "Failure of recovery from lead induced hepatoxicity and disruption of erythrocyte antioxidant defence system in wistar rats," Environmental Toxicology and Pharmacology, vol. 37, no. 3, pp. 1202-1211, 2014.

[43] R. K. Schindhelm, L. P. Van Der Zwan, T. Teerlink, and P. G. Scheffer, "Myeloperoxidase: a useful biomarker for cardiovascular disease risk stratification?" Clinical Chemistry, vol. 55, no. 8, pp. 1462-1470, 2009.
[44] Y. Yabe, N. Kobayashi, T. Nishihashi et al., "Prevention of neutrophil-mediated hepatic ischemia/reperfusion injury by superoxide dismutase and catalase derivatives," The Journal of Pharmacology and Experimental Therapeutics, vol. 298, no. 3, pp. 894-899, 2001.

[45] G. O. Ochigbo, A. B. Saba, A. A. Oyagbemi, T. O. Omobowale, and E. R. Asenuga, "Polyphenol-rich fraction of Parquetina nigrescens mitigates dichlorvos-induced neurotoxicity and apoptosis," Journal of Ayurveda and Integrative Medicine, vol. 8, no. 1, pp. 27-36, 2017.

[46] K. Biswas, A. Kumar, B. A. Babaria, and S. Ramachandra Setty, "Hepatoprotective effect of leaves of Peltophorum pterocarpum against paracetamol induced acute liver damage in rats," Journal of Basic and Clinical Pharmacy, vol. 1, no. 1, pp. 10-15, 2009.

[47] P. K. Sharma, R. Bhardwaj, B. S. Dwarakanath, and R. Varshney, "Metabolic oxidative stress induced by a combination of 2-DG and 6-AN enhances radiation damage selectively in malignant cells via non-coordinated expression of antioxidant enzymes," Cancer Letters, vol. 295, no. 2, pp. 154-166, 2010.

[48] J. C. Okpala, I. Sani, R. Abdullahi, H. N. Ifedilichukwu, and J. C. Igwe, "Effects of n-butanol fraction of Gongronema latifolium leave extract on some biochemical parameters in CCl4- induced oxidative damage in Wistar albino rats," African Journal of Biochemistry Research, vol. 8, no. 2, pp. 52-64, 2014.

[49] O. N. Chinaka, O. O. Julius, and G. A. Motunrayo, "In vitro antioxidant potentials of some herbal plants from Southern Nigeria," Journal of Medical Sciences, vol. 13, no. 1, pp. 56-61, 2013.

[50] A. M. Moussa, A. M. Emam, Y. M. Diab, M. E. Mahmoud, and A. S. Mahmoud, "Evaluation of antioxidant potential of 124 Egyptian plants with emphasis on the action of Punica granatum leaf extract on rats," International Food Research Journal, vol. 18, pp. 535-542, 2011.

[51] C. Larbie, B. O. Emikpe, S. A. Akpor, E. Adams, A. A. Oyagbemi, and T. A. Jarikre, "Ameliorative effect of extract of Tecoma stans (L.) Juss. ex kunth leaves against $\mathrm{CCl}_{4}$ - and acetaminophen-induced liver damage in rats," $\mathrm{Ad}$ vances in Traditional Medicine, 2020. 